Review Article

\title{
Variable Speed Drive Characterization: Review of Measurement Techniques and Future Trends
}

\author{
Edoardo Fiorucci, ${ }^{1}$ Giovanni Bucci, ${ }^{1}$ Fabrizio Ciancetta, ${ }^{1}$ \\ Daniele Gallo, ${ }^{2}$ Carmine Landi, ${ }^{2}$ and Mario Luiso ${ }^{2}$ \\ ${ }^{1}$ Dipartimento di Ingegneria Industriale e dell'Informazione e di Economia, Università dell'Aquila, \\ Via G. Gronchi 18-Pile, 67100 L' Aquila, Italy \\ ${ }^{2}$ Dipartimento di Ingegneria Industriale e dell'Informazione, Seconda Università degli Studi di Napoli, \\ Via Roma 29, 81031 Aversa (CE), Italy
}

Correspondence should be addressed to Mario Luiso; mario.luiso@unina2.it

Received 13 April 2013; Revised 4 June 2013; Accepted 5 June 2013

Academic Editor: Francesco Profumo

Copyright (C) 2013 Edoardo Fiorucci et al. This is an open access article distributed under the Creative Commons Attribution License, which permits unrestricted use, distribution, and reproduction in any medium, provided the original work is properly cited.

\begin{abstract}
The significant advances in power electronics have permitted the implementation of sophisticated methods for control of electric motors. Each innovative electrical apparatus for industrial and automotive application must be correctly and exhaustively tested, both during the developing process and finally for the compliance test. The development of a new electrical system should be associated with a parallel design of an ad hoc measurement system, whose performance should be defined according to the features of the system under test. In recent years, the increasing interest for sensorless electric motor drives involved the development and implementation of a wide set of control techniques. This paper reviews the state and the trends of measurement techniques and instruments applied for the experimental characterization of variable speed drives.
\end{abstract}

\section{Introduction}

The test, monitoring, and maintenance of an electrical variable speed drives (VSDs) involve the measurement of several quantities, both electrical and mechanical.

In detail, the development and the application of sensorless techniques for VSD involve the setting up of measurement system during the validation phase, even by adopting mechanical transducers that will not be present in the final release of the VSD.

Typical electrical quantities are the supply voltage and current and the active power. The measurement of mechanical torque and rotation speed is also required to evaluate the mechanical power produced by the motor. High accuracy measurement of resistance $(R)$ and inductance $(L)$ are needed for the correct implementation of the motors model.

A wide variety of instrument and transducers are available for the measurement of these quantities. Analogue instruments were generally used in the past, even if the recent trend has been toward digital instruments, because of better performance and remote communication capabilities.
Due to the fast advancement of semiconductor power switching device technology and developments in microprocessor-based control systems, actually the VSDs are widespread because of their versatility. The utilization of such control devices makes the supply electrical quantities of the electrical motors strongly deformed [1].

The characterization of a VSD, using traditional techniques and sinusoidal signals, can give incorrect or misleading results, because of the different working conditions. High performance transducers can be successfully adopted for the development of data acquisition systems based on multichannel Data Acquisition Devices (DAQ). The evaluation of the VSD performance should also be investigated by considering PQ phenomena involving the supply voltage waveforms [2$5]$.

\section{Voltage Measurement}

In VSD the definition of the voltage measurement techniques and instrumentation is one of the most interesting topics. 


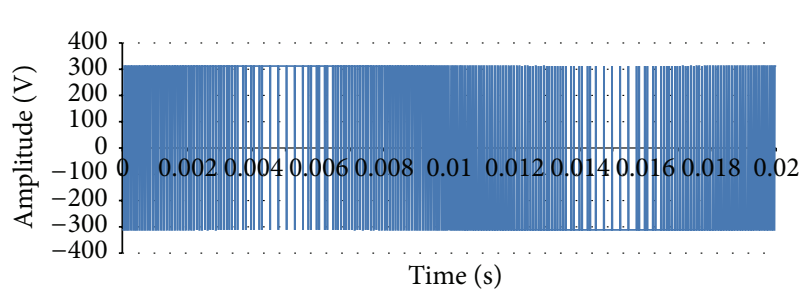

(a)

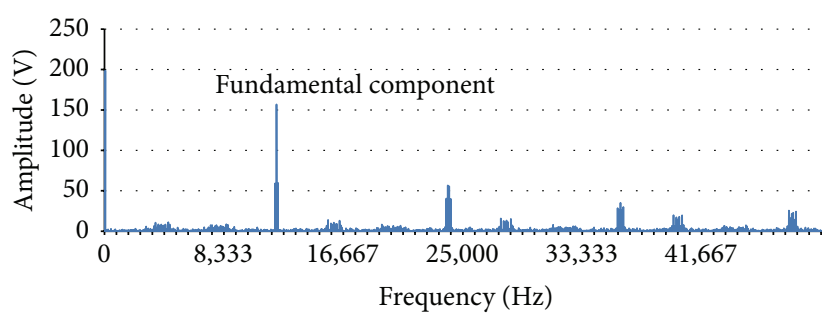

(b)

FIGURE 1: A typical PWM voltage waveform, in time and frequency domains.

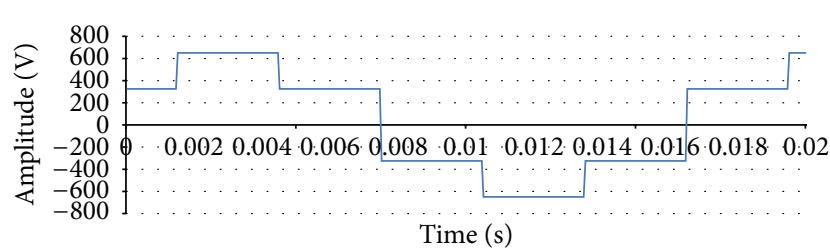

(a)

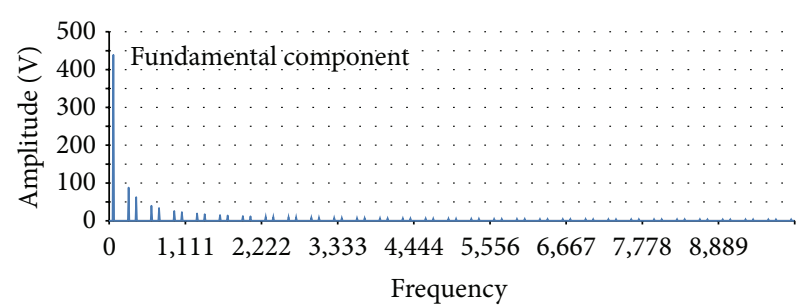

(b)

FIGURE 2: A typical six steps voltage waveform, in time and frequency domains.

Both AC and DC voltage measurements can be required, according to the features of the power electronics devices adopted in the VSD. A digital instrument for AC voltage measurement embodies two main blocks, a voltage conditioner and a low voltage measuring system.

To select the right instrument, different parameters must be analyzed. The nominal voltage root mean square (RMS) value, usually $115 / 230 \mathrm{~V}$ for one-phase and $200 / 400 \mathrm{~V}$ for three-phase configurations, firstly influences the choice of the voltage conditioner, respectively, even if higher voltage amplitudes can be used for high power VSD. A voltage attenuation stage must be provided to supply the right signal level to the electronic measuring system. Moreover, insulation is frequently required.

To measure AC voltage accurately both voltage conditioner and digital instrument must have a suitable bandwidth. For a sine wave, it must be at least as large as the sine frequency.

Nevertheless, considering the usual definition of bandwidth, a signal with a frequency near this value will be decreased by $3 \mathrm{~dB}$, so an even wider bandwidth is desirable for a better measurement.

In some VSD applications the voltage nominal frequency, usually $50-60 \mathrm{~Hz}$, cannot be considered because, using both voltage waveform Pulse Width Modulation (PWM) and sixstep techniques, a strong harmonic distortion occurs (Figures 1 and 2).

In this case, if certain harmonics are outside the instrument bandwidth, their effect on the waveform will not be measured. In order to guarantee the system and operator safety, the voltage conditioner must allow electrical insulation between the system under test and the instrumentation. In addition, the galvanic insulation helps reduce the problems caused by large common-mode voltage.

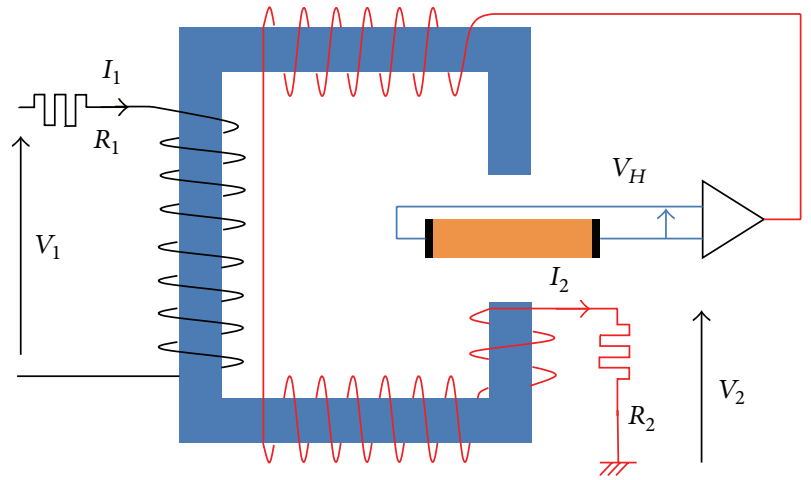

FIGURE 3: Hall effect closed loop voltage transducer.

The largely used voltage transformers allow both voltage reduction and electrical insulation, but their accuracy is assured only at $50-400 \mathrm{~Hz}$. The use of this kind of conditioner introduces filtering effect on the voltage waveform, with unacceptable uncertainty in the amplitude spectra evaluation and instantaneous measurements. A widely used alternative is the Hall effect based voltage transducer, schematically represented in Figure 3.

A Hall sensor is placed in the gap of a flux concentrating magnetic core. The voltage under measurement $V_{1}$, applied to the primary winding, produces the current $I_{1}$. This current attempts to magnetize the core but in doing so generates a potential difference $V_{H}$ across the thin sheet of semiconductor material. The $V_{H}$, amplified, drives the secondary winding and compensates the core flux level. The voltage drop across the resistor $R_{2}$, produced by secondary current $I_{2}$, represents the transducer output.

For applications as VSD and servo motor drives, the use of Hall effect closed loop voltage transducers offers different 
TABLE 1: Electrical features of Hall effect closed loop voltage transducers.

\begin{tabular}{lccc}
\hline$V_{1}$ (range) & $500 \mathrm{~V}$ & $1000 \mathrm{~V}$ & $1500 \mathrm{~V}$ \\
Accuracy at $25^{\circ} \mathrm{C}$ & $0.7-1.0 \%$ & $0.2 \%$ & $0.2 \%$ \\
Accuracy at -40 to $+85^{\circ} \mathrm{C}$ & $0.6 \%$ & $0.6 \%$ & $0.6 \%$ \\
Linearity & $0.1 \%$ & $0.1 \%$ & $0.1 \%$ \\
Offset voltage at $25^{\circ} \mathrm{C}$ & $5.0 \mathrm{mV}$ & $5.0 \mathrm{mV}$ & $5.0 \mathrm{mV}$ \\
Offset voltage at -40 to $+85^{\circ} \mathrm{C}$ & $13.0 \mathrm{mV}$ & $13.0 \mathrm{mV}$ & $13.0 \mathrm{mV}$ \\
Response time $\left(90 \% V_{1 \max }\right)$ & $0.4 \mu \mathrm{s}$ & $0.3 \mu \mathrm{s}$ & $0.4 \mu \mathrm{s}$ \\
Frequency bandwidth from $\mathrm{DC}$ & $400 \mathrm{kHz}$ & $500 \mathrm{kHz}$ & $800 \mathrm{kHz}$ \\
$V_{\text {lRMS }}$ (insulation test) & $6 \mathrm{kV}$ & $6 \mathrm{kV}$ & $6 \mathrm{kV}$ \\
\hline
\end{tabular}

advantages, such as excellent accuracy, very good linearity, low thermal drift, and high immunity to external interferences. Typical features of commercially available transducers (LEM CV family, [6]) are summarised in Table 1.

Unless otherwise specified, AC voltmeters are usually calibrated to read out in RMS values. The conditioner output is generally measured by means of a RMS-to-DC converter and integration DC voltmeter. Typical accuracies, usually valid from $5 \%$ to $100 \%$ of range, are shown in Tables 2, 3, and 4, for different signal frequencies and different digital multimeters (DMM) [7-9].

Another measurement technique is based on the processing of voltage samples supplied by a data acquisition system (DAS). It samples and converts the input signal. Sampling is performed by a Sample and Hold $(\mathrm{S} / \mathrm{H})$ circuit that picks instantaneous input values and maintains them constant. Conversion is performed by an $\mathrm{A} / \mathrm{D}$ converter (ADC) that picks an integer value from a predetermined, finite list of integer numbers to represent each analog sample.

After the process of digitization a discrete input signal is translated in a sequence of $n$-bit digital words. They are affected by a quantization error bounded by $\pm 1 / 2$ LSB = $\pm 1 / 2 \mathrm{Vfs} / 2 n$, where $\mathrm{Vfs}$ is the full scale ADC range. The ideal average error is 0 LSB and the standard deviation of error is $1 / \sqrt{12}$ LSB. The relation between the signal-to-noise ratio of a digitized signal and the ADC bit number, expressed by SNR $=1.76+6.02 n(\mathrm{~dB})$, is shown in Table 5 .

The main advantage of a DAS, compared with a voltmeter, is the possibility to analyze the voltage shape, for example, by means of a spectrum analysis. Moreover a single DAS allows more than one voltage to be measured at the same time. This is important because the characterization of a three-phase VSD generally requires the measurement of 3 voltages, 3 currents, and 2 analog or digital signals generated by torque and angular velocity transducers.

\section{Current Measurement}

Current can be measured by a RMS ammeter or by a DAS. Both systems convert the current signal to a voltage, which is measured using the blocks discussed in previous section. Typical accuracies for low-range RMS ammeters are shown in Table $6[7,8,10,11]$. Greater range ammeters generally present worse accuracies, as shown in Table 7 , for different signal frequencies [9].

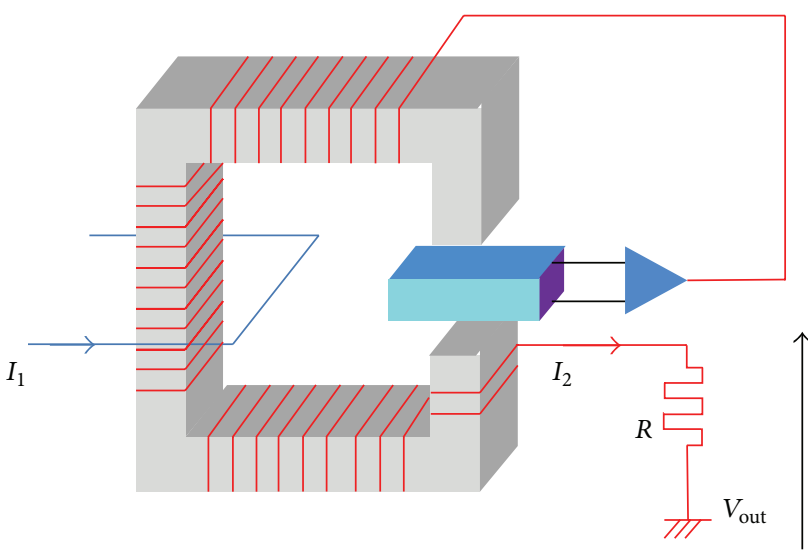

FiguRE 4: Hall effect closed loop current transducer.

In case of a high supply voltage, electrical insulation must be provided. Current transformers are widely used, but the problem is still the operating frequency, which must be around $50 \mathrm{~Hz}$, even if their bandwidth is greater than that of the voltage transformers. Because current signal is generally more distorted than voltage, a bandwidth greater than that for voltage measurement is required. In this case these devices cannot be used.

Moreover, these problems imply more difficulties in the implementation of the RMS AC-to-DC converter of the ammeter or of the DAS measurement algorithm. Alternative solutions are noninductive resistor shunts (for the $I / V$ conversion) or Hall based current transducers (Figure 4). The better amplitude accuracy combined with the smallest phase angle error is offered by the coaxial low inductive and low capacitive shunts, as reported in Table 8 [12]. Moreover they are passive components that do not cause offset.

The main disadvantage is that output of the shunts is not galvanically separated from the measured potential.

This means that a DMM that works with shunts needs sufficient common mode rejection at high frequencies or a further galvanic insulation, innate in the Hall based systems. But the latest ones present a linear response only in a defined working interval.

\section{Power Measurement}

In the past active power at line frequency was generally measured by a dynamometer. But today the use of wideband electronic instruments has become unavoidable. For precise power measurement a high-performance power meter is necessary, especially when the motor current is extremely distorted because of small inductances and capacitances of the motor.

Today the switching frequencies of power electronics applications can be as high as some hundreds of kilohertz and the trend is rising. Therefore, the measurement of power components in nonsinusoidal conditions may be a bit of a problem [13-18], that is, to measure the switching losses in a motor. 
TABLE 2: Accuracy (\% reading + \% range) specifications for the 8.5 digit Agilent 3458A DMM.

\begin{tabular}{lccccc}
\hline \multirow{2}{*}{ Range } & \multirow{2}{*}{ Resolution } & \multicolumn{3}{c}{ Signal bandwidth } \\
& & $40-100 \mathrm{~Hz}$ & $0.1-20 \mathrm{kHz}$ & $20-50 \mathrm{kHz}$ & $50-100 \mathrm{kHz}$ \\
\hline $100 \mathrm{~V}$ & $100 \mu \mathrm{V}$ & $(0.06+0.01)$ & $(0.03+0.01)$ & $(0.15+0.04)$ & $(0.6+0.08)$ \\
$1000 \mathrm{~V}$ & $1 \mathrm{mV}$ & $(0.08+0.02)$ & $(0.06+0.02)$ & $(0.15+0.04)$ & $(0.6+0.2)$ \\
\hline
\end{tabular}

TABLE 3: Accuracy (\% reading + \% range) specifications for the 7.5 digit Prema 5017 DMM.

\begin{tabular}{ccccc}
\hline \multirow{2}{*}{ Range } & \multicolumn{4}{c}{ Signal bandwidth } \\
& $20-40 \mathrm{~Hz}$ & $20 \mathrm{~Hz}-1 \mathrm{kHz}$ & $20 \mathrm{~Hz}-50 \mathrm{kHz}$ & $20 \mathrm{~Hz}-100 \mathrm{kHz}$ \\
\hline $200 \mathrm{~V}$ & $0.2+0.01$ & $0.5+0.01$ & $0.1+0.02$ & $0.5+0.1$ \\
$700 \mathrm{~V}$ & $0.2+0.01$ & $0.5+0.01$ & $0.1+0.02$ & $0.5+0.1$ \\
\hline
\end{tabular}

TABLE 4: Accuracy specifications for the handheld Fluke 187-189 DMM.

\begin{tabular}{lccccc}
\hline \multirow{2}{*}{ Range Resolution } & \multicolumn{4}{c}{ Signal bandwidth } \\
& & $45-1000 \mathrm{~Hz}$ & $1-10 \mathrm{kHz}$ & $10-20 \mathrm{kHz}$ & $20-100 \mathrm{kHz}$ \\
\hline $50 \mathrm{~V}$ & $0.001 \mathrm{~V}$ & $0.4 \%$ & $0.4 \%$ & $1.5 \%$ & $8 \%$ \\
$500 \mathrm{~V}$ & $0.01 \mathrm{~V}$ & $0.4 \%$ & $0.4 \%$ & $1.5 \%$ & $8 \%$ \\
\hline
\end{tabular}

Some electronic wattmeters use an analog multiplier, such as the TDM (Time-Division Multiplier) or that based on the Hall effect (Figure 5). Modern digital power meters sample both voltage $u(t)$ and current $i(t)$ signals and calculate the power by processing the samples in the time domain $[19,20]$. The quadratic integration of the sample values of voltage $u_{k}$ and current $i_{k}$ gives the RMS values for voltage $U$ and current I.

The integration of the product $p_{k}=u_{k} \cdot i_{k}$ over the signal period results in an average value for active power $U$. A multiplication of the averaged values of voltage $U_{\text {RMS }}$ and current $I_{\mathrm{RMS}}$ results in the apparent power $S$.

The power factor is calculated by dividing active power $P$ by apparent power $S$. Active power can also be measured starting from voltage and current frequency components [13, 21, 22].

Voltage and current must be sampled at the same time, imposing at the two acquisition channels the same time delay and at the system (e.g., a DAS) the simultaneous sampling capability.

As the DAS is concerned, it can embody a number or only one $\mathrm{S} / \mathrm{H}$ circuit. In the last case $u_{k}$ and $i_{k}$ samples are acquired at different points in time, making difficult and imprecise their correlation. Different problems affect the power measurement. To calculate the power integral, the exact knowledge of the signal period is of primary importance. Unfortunately this measurement is not simple to be made, especially in the presence of high signal distortion (e.g., PWM).

Problems can arise in the analog front-end of the wattmeter, mainly due to the step rise of electrical quantities (e.g., $10 \mathrm{~V} / \mathrm{ns}$ ) and different positive and negative slew rate of active elements.

To get accurate power values it is quite important that the $u(t)$ and $i(t)$ signals must be sampled at absolutely the same
TABLE 5: Signal-to-noise ratio for different value of $n$.

\begin{tabular}{lcccccccc}
\hline SNR & 13.8 & 25.8 & 37.9 & 49.9 & 62.0 & 74.0 & 86.0 & 98.1 \\
\hline Bit number & 2 & 4 & 6 & 8 & 10 & 12 & 14 & 16 \\
\hline
\end{tabular}

TABLE 6: True RMS ammeter accuracy (\% read + \% range) specifications.

\begin{tabular}{lcccc}
\hline Instrument & Digit & Range & Band & Accuracy \\
\hline Agilent 3458A & 8.5 & $100 \mu \mathrm{A}-1 \mathrm{~A}$ & $10 \mathrm{~Hz}-100 \mathrm{kHz}$ & $0.08+0.02$ \\
Keithley 2002 & 8.5 & $200 \mu \mathrm{A}-2 \mathrm{~A}$ & $20 \mathrm{~Hz}-100 \mathrm{kHz}$ & $0.2+0.015$ \\
Fluke 1281 & 8.5 & $100 \mathrm{~mA}-2 \mathrm{~A}$ & $10 \mathrm{~Hz}-5 \mathrm{kHz}$ & $0.1+0.03$ \\
Prema 5017 & 7.5 & $200 \mu \mathrm{A}-2 \mathrm{~A}$ & $20 \mathrm{~Hz}-5 \mathrm{kHz}$ & $0.2 \mathrm{~b}+0.01$ \\
\hline
\end{tabular}

TABLE 7: Accuracy specifications for the handheld Fluke 187-189 DMM.

\begin{tabular}{lccc}
\hline \multirow{2}{*}{ Range } & \multirow{2}{*}{ Resolution } & \multicolumn{2}{c}{ Signal bandwidth } \\
& & $45-1000 \mathrm{~Hz}$ & $1-20 \mathrm{kHz}$ \\
\hline $5 \mathrm{~A}$ & $0.0001 \mathrm{~A}$ & $1.5 \%$ & $6 \%$ \\
$10 \mathrm{~A}$ & $0.001 \mathrm{~A}$ & $1.5 \%$ & $5 \%$ \\
\hline
\end{tabular}

time. When the power factor is less than 0.5 , or the frequencies above $400 \mathrm{~Hz}$, the time shift of one signal against the other caused by nonsynchronous sampling is very critical.

A time shift caused by any differences in the time each channel is sampled will result in a large error of the active power reading. The PWM is one of the hardest waveforms to analyze for the electronic wattmeters $[16,17,23]$. Within a few nano- or microseconds the signals in power electronics applications alternate from maximum potential to zero and back to maximum potential.

To multiply sample values of voltage and current, which really belong together, neither the analog inputs nor the instrument, probes or transducers should cause a time shift between the signals.

The four most important characteristics of digital wideband power meters are amplitude accuracy bandwidth, phase angle errors of inputs and transducers, and common mode rejection.

As an example the accuracy specification for the high-performance Norma D6000 [24] wattmeter has been reported. For this wideband $(1 \mathrm{MHz})$ instrument we report the accuracy in the measurement of voltage (Table 9a), current (Table 9a), and power (Table 9b).

\section{Measurement of Mechanical Quantities}

The measurement of a mechanical quantity, essentially torque and rotor speed, requires a sensor or transducer with suitable 
TABLE 8: Accuracy specifications for LEM triaxial shunts (range 0.003-30 A).

\begin{tabular}{lcccc}
\hline Basic accuracy & Angular accuracy & Frequency influence & Load influence & Temperature coefficient \\
\hline \pm 0.03 & $\pm 0.001^{\circ} / \mathrm{kHz}$ & $\pm 0.0015 \% / \mathrm{kHz}$ & $\pm 10^{-6} \% / \mathrm{A}_{2}$ & $<15 \mathrm{ppm} / \mathrm{K}$ \\
\hline
\end{tabular}

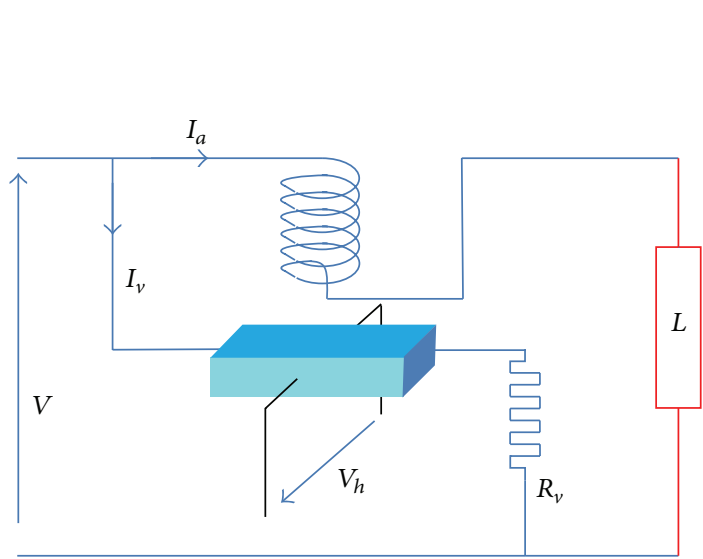

Hall effect low frequency wattmeter

(a)

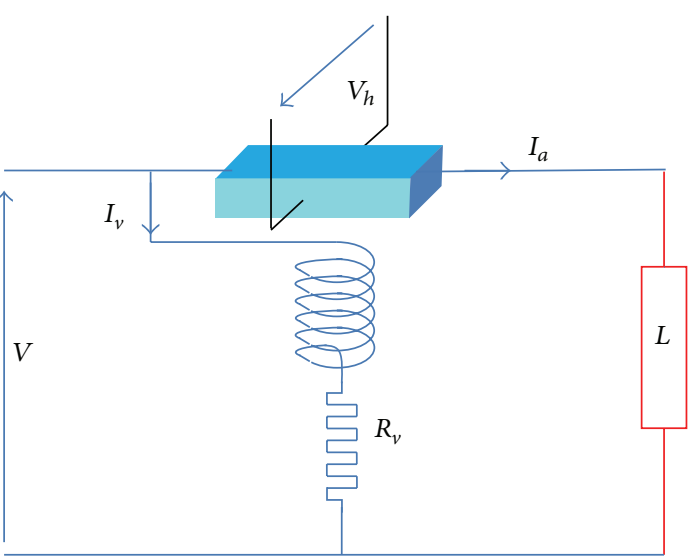

Hall effect high frequency wattmeter

(b)

FIgURE 5: Configurations of the Hall based wattmeter.

performance, accuracy, and cost. Moreover, the band of the sensor must be adequate with that of the signal, to analyze all the frequency components and decrease measurement error. The measurement of torque and rotor speed causes additional challenges.

5.1. Angular Velocity Measurement. The angular velocity of the motor is generally measured by means of a tachometer. Typical low-ripple DC tachometers features are reported in Table 10. However, when applied to an inverter-based system the disturbances could cause an offset of the analog signal output.

Because digital signals are not so easy to disturb, other solutions adopt a magnetic pick-up or an optical encoder, to generate a frequency-modulated signal, which can be converted by means of a frequency-to-voltage converter and then measured [25]. The encoder resolution is strictly related to the amount of mechanical play or elastic coupling. Measurement accuracy is about $0.025 \%$.

The system can allow both relative and absolute measurement readings. A relative reading encoder gives an indication of a previous position plus an increment. In this case the degree of accuracy is related to the unit of resolution of the encoder. Incremental information (Figure 6) consists of a two-bit (A, B) Gray code in quadrature (duty cycle of 50\%). The difference between the two bits is 90 electrical degrees, but the direction of rotation is needed. A reference point indicates the completion of the revolution.

The absolute encoder gives precision position in the form of signal codes (Figure 7).

It clearly indicates the direction of increment and the value without calculations. The encoders generally use the Gray, Binary, BCD, and ASCII codes. The main feature of Gray code is the chance of only one bit at once, which makes possible to precisely identify the encoder output in very noisy environments. The Binary code is useful in fast applications, when it is necessary to save time to convert the code. The BCD is useful in systems, which require a direct display of the value assumed by the encoder. The ASCII allows the encoder to communicate directly with a PC or a serial system.

A problem is the measurement at low speed, because encoder pulses and sampling signal (from a DAS or a different measuring system) are not synchronous [25]. Moreover, electromagnetic spikes on the encoder output signal can alter the measurement result by increasing the number of counted pulses.

5.2. Mechanical Torque Measurement. The measurement of mechanical torque is generally carried out by means of sensing elements that detect the strain and compression of the shaft surface in the main direction of stress [26], or the twist angle of the shaft. At this aim, Table 11 resumes the main measurement techniques. In the first case strain gauges in the Wheatstone full bridge configuration are glued onto the shaft. In the latter case, sensor wheels, disks, cases, or perforated disks are placed to the left and right of a torsionally compliance section of the shaft. A torque application produces a torsional twisting and then an angle deflection of the torque bar, proportional to both bar length and applied torque, and inversely proportional to the fourth power of bar diameter. Torque is obtained by measuring the rotation (reciprocal phase) of these sensing elements.

The output of a conditioning circuit is measured by means of a DAS or a voltmeter.

Another technique is based on the measurement of the reaction torque, that is, the torque required to block the stator when the rotor is turning, measured by mounting the stator frame free to rotate and connecting a force transducer 
TABle 9: (a) Accuracy \pm ( $\%$ reading $+\%$ range) for $V$ and $I$. (b) Accuracy \pm ( $\%$ of reading) for $P$.

(a)

\begin{tabular}{lcc}
\hline Frequency $[\mathrm{Hz}]$ & Voltage & Current \\
\hline $0-15$ & $\pm(0.15+0.03)$ & $\pm(0.15+0.05)$ \\
$15-45$ & $\pm(0.15+0.01)$ & $\pm(0.15+0.03)$ \\
$45-1000$ & $\pm(0.04+0.01)$ & $\pm(0.04+0.02)$ \\
$1 \mathrm{k}-400 \mathrm{k}$ & $\pm[(0.04+0.0045 / \mathrm{kHz})+(0.01+0.003 / \mathrm{kHz})]$ & $\pm[(0.04+0.0045 / \mathrm{kHz})+(0.02+0.0045 / \mathrm{kHz})]$ \\
$400 \mathrm{k}-1 \mathrm{M}$ & typ.: $-0.5 \%$ of rdg./100 kHz & $2 \%$ of rdg $/ 100 \mathrm{kHz}$ \\
\hline
\end{tabular}

(b)

\begin{tabular}{lccc}
\hline Frequency & & Power factor $(\cos \Phi)$ & 0.1 \\
\hline $1 \mathrm{~Hz}$ & 1 & 0.5 & 0.313 \\
$50 \mathrm{~Hz}$ & 0.296 & 0.296 & 0.138 \\
$1 \mathrm{kHz}$ & 0.089 & 0.091 & 0.238 \\
$10 \mathrm{kHz}$ & 0.089 & 0.097 & 1.32 \\
$100 \mathrm{kHz}$ & 0.211 & 0.31 & - \\
$400 \mathrm{kHz}$ & 1.32 & 2.5 & - \\
\hline & 5.04 & - & 0.001 \\
\hline $50 \mathrm{~Hz}$ & & Power factor $(\cos \Phi)$ & 4.64 \\
\hline & 0.1 & 0.01 & $10 \%$ \\
\hline $50 \mathrm{~Hz}$ & 0.1 & 0.472 & 0.175 \\
\hline
\end{tabular}

TABLE 10: Typical features for a tachometer.

\begin{tabular}{lccc}
\hline Output voltage & Linearity & RMS ripple & Accuracy \\
\hline $1-10 \mathrm{~V} / 1000 \mathrm{rmp}$ & $<0.1 \%$ & $<1.5 \%$ & $0.25 \%$ \\
\hline
\end{tabular}

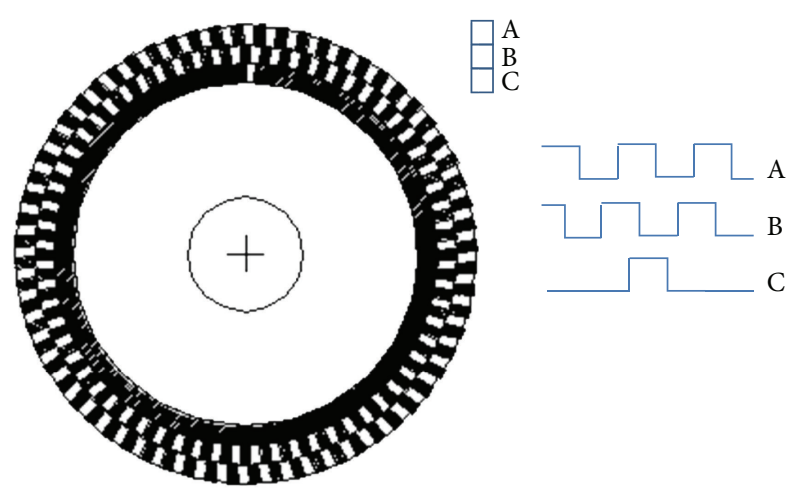

FIGURE 6: Incremental encoder disk and phases.

between the stator and a fixed connection point. Torque sensing elements (torque bars) are inserted between the driving motor and the driven shaft.

The main torque measurement problems are induced by the sensors, which are affected by hysteresis and nonlinearities, and sensitivity to external temperature variations.

Moreover their response time is very high (some milliseconds), introducing a delay from the torque generation and its measurement. This means also that some dynamic events (i.e., torque fluctuations or torsional vibrations) cannot be measured [27].

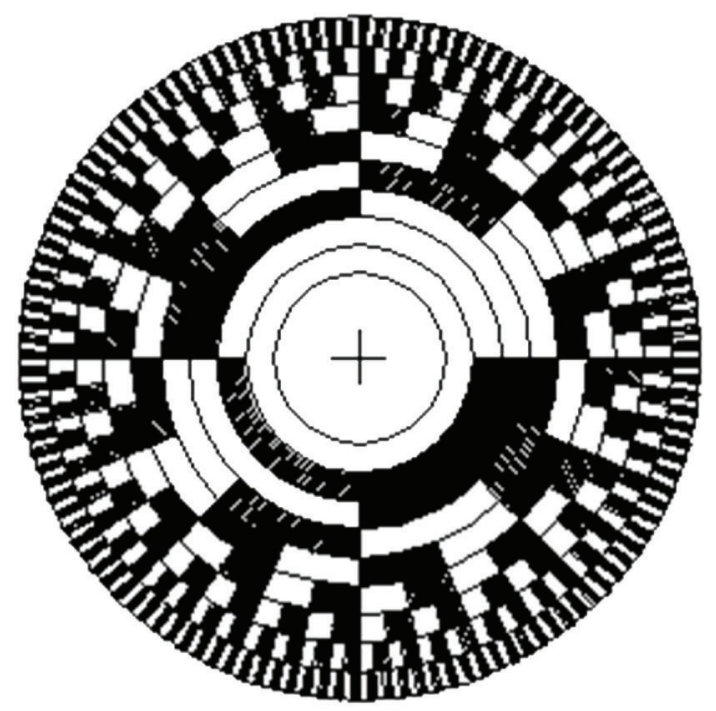

Figure 7: Absolute encoder disk.

Sensors based on strain gauges are characterized today by good accuracy (see Table 12), but they are subjected to restrictions concerning the maximum number of revolution (several thousand rpm). Twist-angle sensing devices are of increasing importance for cost reasons and because of their contact-free operation principle. In case of inductive transmitters, which function according to the transformer principle, $50000 \mathrm{rpm}$ are possible.

Table 13 reports the typical features for rotating torque transducers produced by the Hottinger Baldwin Messtechnik [28]. 
TABLE 11: Torque measurement techniques.

\begin{tabular}{|c|c|c|}
\hline \multicolumn{3}{|c|}{ Rotating system } \\
\hline \multirow{5}{*}{ Strain sensitive } & \multirow{3}{*}{$\begin{array}{l}\text { Strain gauges } \\
\text { and similar }\end{array}$} & Strain gauges \\
\hline & & Torsion bars with different cross section \\
\hline & & Cruciform cross section with linear strain gauges glued on bending beams. \\
\hline & \multirow{2}{*}{ Magnetostrictive effects } & Coil systems with induced eddy current in the shaft \\
\hline & & Coil systems with change of permeability of the shaft \\
\hline \multirow{7}{*}{ Torque angle sensitive } & \multirow{4}{*}{$\begin{array}{l}\text { Toothed wheels, } \\
\text { slotted collars, } \\
\text { stamped rings }\end{array}$} & Phase detection by magnetic pickups \\
\hline & & Coils systems with slotted collars \\
\hline & & Coil systems with torsional variable differential transformer \\
\hline & & Encoder disks with Led-photocell arrangement \\
\hline & \multirow{3}{*}{$\begin{array}{l}\text { Transmission } \\
\text { to linear displacement } \\
\text { by lever }\end{array}$} & Transmission by lever to inductive differential gap sensor \\
\hline & & Transmission to string vibration transducer \\
\hline & & Transmission to linear variable differential transformer \\
\hline \multicolumn{3}{|c|}{ Reaction system } \\
\hline \multirow{2}{*}{ Strain sensitive } & \multirow{2}{*}{ Strain gauge } & Torsion bars with different cross sections \\
\hline & & Transmission to strain sensitive bending beams or platforms \\
\hline $\begin{array}{l}\text { Force or displacement } \\
\text { sensitive }\end{array}$ & $\begin{array}{l}\text { Strain gauges, piezoelectrics, and } \\
\text { others }\end{array}$ & Cantilever with different kind of force and displacement transducers \\
\hline
\end{tabular}

TABLE 12: Typical features for strain gauges.

\begin{tabular}{lccccc}
\hline Range $[\mathrm{Nm}]$ & Excitation voltage & Sensitivity & Repeatability & Nonlinearity & Hysteresis \\
\hline $10-100$ & $10-15 \mathrm{~V}$ & $1 \mathrm{mV} / \mathrm{V}$ & $<0.15 \%$, & $<0.25 \%$, & $<0.25 \%$. \\
\hline
\end{tabular}

TABLE 13: Rotating torque transducer features.

\begin{tabular}{lcc}
\hline Nominal torque [Nm] & Nominal speed [rpm] & Accuracy class [\%] \\
\hline $0.1-200$ & 10000 & 0.1 \\
$1-20$ & 40000 & 0.2 \\
$10-200$ & 4000 & 0.1 \\
$50-1 \mathrm{k}$ & 4000 & 0.1 \\
$50-10 \mathrm{k}$ & $8000-15000$ & 0.1 \\
$50-25 \mathrm{k}$ & $11000-20000$ & $0.1-0.2-0.3$ \\
\hline
\end{tabular}

In the future surface acoustic wave resonators and strain sensitive fiber optic sensors applied line strain gauges will be available on the market.

\section{Sensorless Control for Electric Motors: Measurement Aspects}

Today, the requirements for VSD are pushing the need to eliminate bulky driveshafts and gearing by placing a directdrive motor at the exact location where torque is required. In such a configuration, the rotor position sensor that is normally required for vector control of the electric motors often cannot be accommodated due to reliability concerns. The position sensorless motor control strategy in which stator windings themselves are used as the rotor position sensor can be successfully adopted in such application [29]. In the literature numerous sensorless strategies for electric motor control have been proposed and investigated, and many approaches for manipulating the electric motors equations have been implemented, to define observers for estimating parameters as fluxes, speed, or position. Lots of physical systems can be modelled by using a state-space description, by using the Kalman filtering [30-35].

Induction motors are today the most widely used ac machines due to the advantageous mix of cost, reliability, and performance [36].

Torque control in induction motors can be achieved according to different techniques ranging from the inexpensive constant voltage/frequency ratio strategy to the sophisticated field-oriented control (FOC) (Figure 8). If a precise and fast torque and flux control is required, FOC is mandatory. In fact only by acting onto the two components of the stator current, in phase and in quadrature with the rotor flux, it is possible to decouple the control of torque and flux, obtaining high dynamic performances comparable with those of dc and brushless drives. Any FOC scheme requires the knowledge of the position of rotor flux vector to properly control the two components of the stator current. Based on the method used to obtain the position of the rotor flux two main classes of FOC schemes are usually defined: (a) the indirect fieldoriented control (IFOC) technique that predicts the position of the rotor flux by means of the model of the induction motor.

Being essentially an open-loop predictive approach IFOC is very sensitive to variations of motor parameters, specifically of the rotor time constant; (b) the direct field-oriented control (DFOC) approach, where the position of the rotor flux is computed from the airgap flux vector position, is directly measured by suitable flux sensing devices or computed from measured stator currents and voltages. 


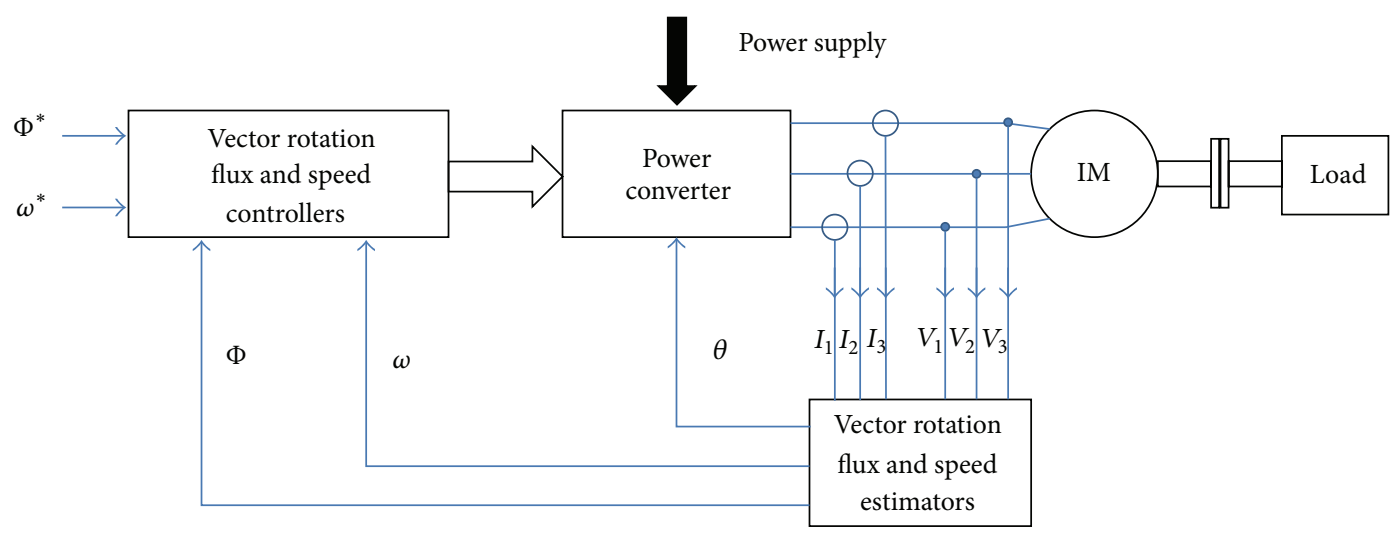

FIGURE 8: Sensorless FOC system.

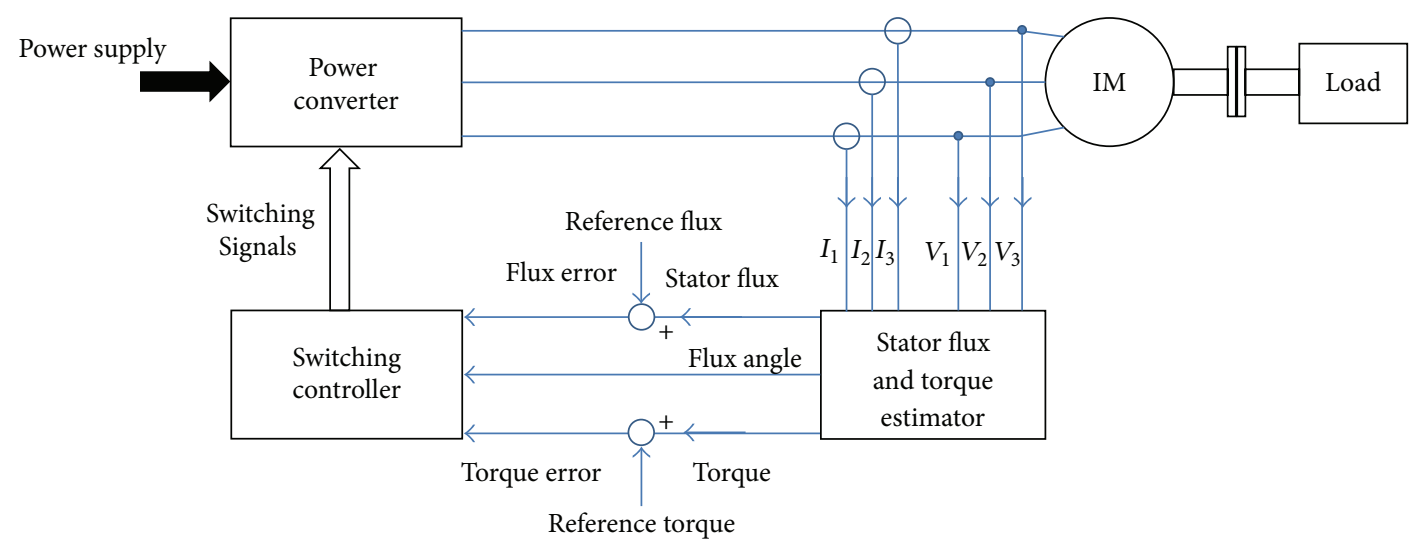

FIGURE 9: Block diagram of DSC.

DFOC is less sensitive to motor parameters variations than IFOC, but its practical implementation is often complex, due to the need to place flux sensors, such as Hall effect based devices, in standard induction motors; moreover, precise lowspeed operations are very difficult to perform.

Direct self-control (DSC) is a recently introduced control methodology $[37,38]$ that can be considered as the simplest FOC scheme (Figure 9).

For automotive applications with squirrel-cage induction motors, the direct torque control (DTC) is one of the most attractive [39-41].

The required measurements for this control technique are only the input currents. Flux, torque, and speed are estimated. The input of the motor controller is the reference speed, which is directly required by the user. The DTC technique is based on the direct stator flux and torque control [42-48].

6.1. Rotor Resistance Estimation. One of the critical measurement problems in the described strategy is the evaluation of the inductive and resistive parameters of the electric motors; in many cases, under the hypothesis of no magnetic saturation, the inductance parameters are constant, and their value can be measured with traditional off-line testing of the motors.

On the contrary, the resistance parameters must be evaluated on-line. In detail, the stator resistance $R_{T}$ can be estimated by updating the value measured offline by adopting thermal sensors measuring the stator winding temperature; $R_{S}$ can be estimated based on sensitivity of torque, reactive power, or other motor characteristics versus parameter $R_{T}$, and the accuracy of the adopted method directly influences the overall efficiency of the flux estimation as in (2) [47]. Because of the close relationship between the slip speed and rotor resistance, by knowing synchronous and motor speeds (in fact slip speed), estimation of rotor resistance will be easy; but at any time the motor supply voltage is dictated by its flux and torque. The large harmonic content of the supply voltage leads to large fluctuation of the estimated parameters, particularly the speed of the induction motor. Since the motor torque is directly controlled, it has limited oscillation amplitude. Obviously the fluctuation of the estimated speed causes fluctuation of the estimated rotor resistance.

Different techniques based on the error estimation and then modification of the rotor resistance are applicable in the sensorless DTC technique. The most adopted are (i) Reactive Power Error (RPE), in which the error signal is the difference between the references and estimated reactive powers; (ii) Torque Error (TE) in which the signal error is the difference between the reference and actual electric torque values; (iii) Error Function Based on Stator Voltage (EFSV), based on the hypothesis that the torque signal is equal to the product of flux and current. To stabilize the technique, initially 


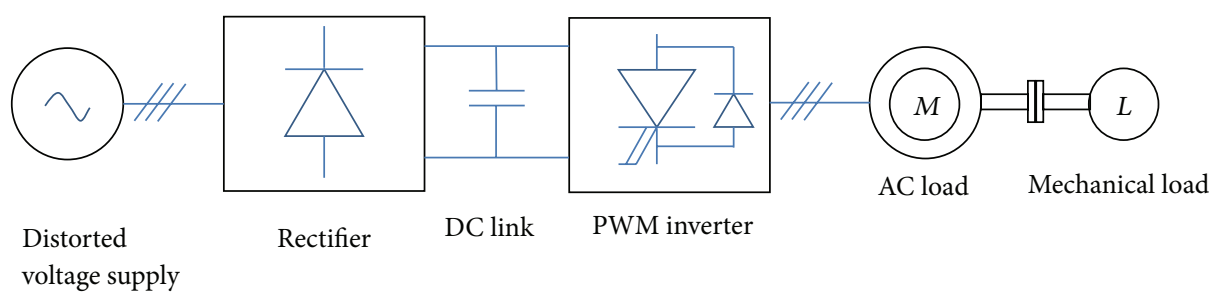

FIgUre 10: AC/DC/AC conversion system with PWM inverter.

the components of voltage have been integrated for reduction of harmonics and then two corresponding current components have been multiplied. In order to convert the above error signals to rotor resistance error and finally to modify the rotor resistance, a PI or PID controller can be used.

\section{PQ Effects on VSD Experimental Characterization}

VSDs are usually designed to operate in sinusoidal conditions. If the VSD is supplied by a system affected by the typical Power Quality (PQ) disturbances (unbalances, harmonics and interharmonics, dips, etc., [2-5]) electrical supply of the induction motor becomes strongly deformed, then the machine behavior changes so much that some machine characteristics or parameters become not easily definable or even lose their physical significance [49].

So, it is interesting to analyze the low frequency conducted electromagnetic disturbances affecting VSDs and to discuss the performance testing procedure for the supplied induction motor characterization under static working conditions, utilizing a suitable measurement station. As an example, the voltage waveforms produced by a PWM inverter could be considered, in order to evaluate the effect introduced in these waveforms by typical electric low frequency steady state disturbances present in the supply system and transferred through the dc link of the double stage converter to the motor terminals.

The PQ phenomena to apply to the VSD for the performance testing can be identified by considering the IEC and IEEE Standards [49-54]; a particular attention can be given to the steady state voltage distortion, whose compatibility levels for harmonic voltage components and voltage unbalance reported in the IEC Standard 61000-2-4 [55] with reference to the class 2 of electromagnetic environment. The design of a testing setup must be performed by considering the features of the VSD to be tested; in this paper we consider a common small power VSD, equipped with a three-phase AC/DC/AC PWM converter, whose main features are in Table 14. Reference is made to the scheme of Figure 10.

The apparatuses we adopted for the testing setup are (Figure 11):

(i) arbitrary waveform power generator (Pacific Power source 3120AMX), [56]

(ii) power analyzer (Norma D6000), [12]

(iii) hysteresis dynamometer (Magtrol HD-715, [57]),
TABLE 14: Specifications of the testing setup.

\begin{tabular}{|c|c|}
\hline \multicolumn{2}{|c|}{ Power supply } \\
\hline Amplitude (r.m.s.) & $380 \mathrm{~V}$ \\
\hline Frequency & $50 \mathrm{~Hz}$ \\
\hline \multicolumn{2}{|c|}{ Rectifier } \\
\hline \multicolumn{2}{|c|}{ Six pulse uncontrolled } \\
\hline \multicolumn{2}{|c|}{$P W M$ inverter } \\
\hline Switching frequency & $\approx 5 \mathrm{kHz}$ \\
\hline \multicolumn{2}{|c|}{ DC Link } \\
\hline Capacitance & $2 \mathrm{mF}$ \\
\hline \multicolumn{2}{|c|}{ Induction motor } \\
\hline Nominal power & $1.2 \mathrm{kVA}$ \\
\hline \multicolumn{2}{|c|}{ Mechanical Load } \\
\hline Nominal torque & $3.5 \mathrm{Nm}$ \\
\hline Nominal speed & $2800 \mathrm{rpm}$ \\
\hline
\end{tabular}

(iv) programmable dynamometer controller (DSP6000, [58]),

(v) blower [57],

(vi) PXI Data Acquisition system [59].

The main characteristics of the 3-phase arbitrary waveform power generator produced by Pacific Power (model 3120AMX, [56]) are (i) Maximum Power: $12 \mathrm{kVA}$; (ii) Frequency Range: $20 \mathrm{~Hz}$ to $50 \mathrm{kHz}$; (iii) Line Regulation: $0.027 \mathrm{mV}$; (iv) Load Regulation: $0.00135 \mathrm{mV}$; (v) THD: 0.1\%; (vi) Voltage Ripple and Noise: $-70 \mathrm{~dB}$.

The hysteresis dynamometer is the Magtrol HD-715 equipped with a programmable controller DSP6000. The dynamometer main characteristics are speed accuracy $0.01 \%$ of reading from $10 \mathrm{rpm}$ to $100000 \mathrm{rpm}$ and torque accuracy $0.25 \%$ of range with a maximum measurable torque of $6.5 \mathrm{Nm}$.

All the instrumentations are controlled by a PXI system produced by National Instruments (model PXI-1020) equipped with a controller NI PXI 8176 with a $1.2 \mathrm{GHz}$ processor, and $128 \mathrm{MB}$ ram, data acquisition board NI PXI-4472, arbitrary waveform generation board NI PXI-5411.

The software implementing the test procedures and coordinating the devices has been developed in NI LabVIEW environment and everything has been made automatic, thanks to the remote control of all the instruments [60].

In order to quantify the effects on the VSD of Power Quality problems, eight different supply voltage conditions were defined. The tests are performed adopting one supply 


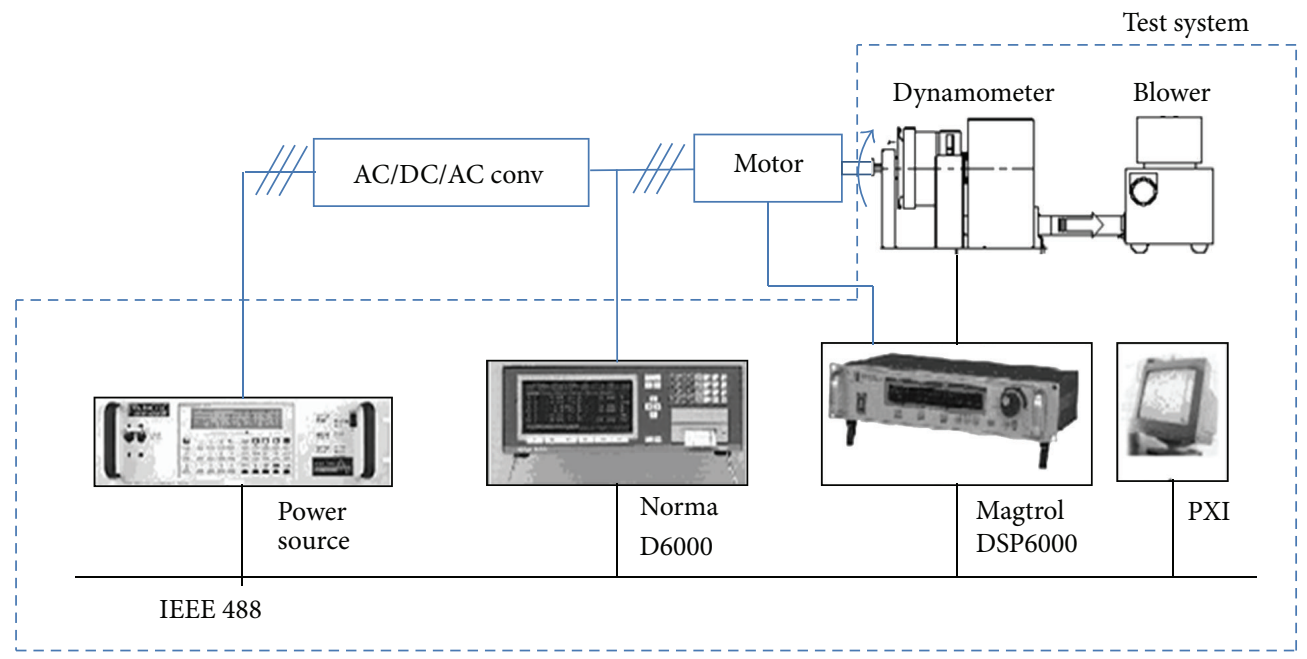

FIgURE 11: The testing setup.

TABLE 15: Harmonic distortion case study.

\begin{tabular}{lcccccc}
\hline $\begin{array}{l}\text { Type of } \\
\text { supply }\end{array}$ & \multicolumn{7}{c}{$\begin{array}{c}\text { Superimposed harmonic distortion } \\
\text { [\% of the fundamental] } \\
h=3\end{array}$} & $h=5$ & $H=7$ & $h=9$ & $h=11$ & $h=13$ \\
\hline \# & 0 & 0 & 0 & 0 & 0 & 0 \\
$\# 2$ & 5 & 0 & 0 & 0 & 0 & 0 \\
$\# 3$ & 5 & 6 & 0 & 0 & 0 & 0 \\
$\# 4$ & 5 & 6 & 7 & 0 & 0 & 0 \\
$\# 5$ & 5 & 6 & 7 & 1.5 & 0 & 0 \\
$\# 6$ & 5 & 6 & 7 & 1.5 & 3.5 & 0 \\
$\# 7$ & 5 & 6 & 7 & 1.5 & 3.5 & 3 \\
\hline \multicolumn{7}{c}{ Unbalance [\%] } \\
\# 8 & 5 & \multicolumn{7}{c}{3} \\
\hline
\end{tabular}

TABLE 16: Mechanical load condition case study.

\begin{tabular}{llllll}
\hline \multicolumn{5}{c}{ Mechanical load [\%] } \\
\hline 0 & 20 & 50 & 80 & 100 & 120 \\
\hline
\end{tabular}

voltage condition of Table 15 for the VSD and, at the same time, fixing one of the mechanical load condition ranging from $20 \%$ to $120 \%$, listed in Table 16 . All the combinations of the eight distorted supply conditions and of the six mechanical load conditions are considered and evaluated.

The performance evaluation can be performed by measuring the simplest compact indexes which are considered: THDI, THDV, and efficiency.

The software implementing the test procedures and coordinating the devices has been developed in NI LabVIEW environment.

As preliminary results of performance of a real motor in an ASD system, three of the simplest compact indexes are considered: THDI, THDV, and efficiency.
The THID and THDV are evaluated as follows:

$$
\begin{aligned}
\mathrm{THDI} & =\sqrt{\sum_{k=2}^{N} \frac{I_{k}^{2}}{I_{1}^{2}}} \\
\mathrm{THDV} & =\sqrt{\sum_{k=2}^{N} \frac{V_{k}^{2}}{V_{1}^{2}}},
\end{aligned}
$$

where $I_{k}$ and $V_{k}$ are the $k$ th current and voltage harmonic component, respectively, and $N$ is the maximum order of measured harmonic component.

The efficiency is evaluated as follows:

$$
\eta=\frac{P_{m}}{P_{e}}
$$

being $P_{m}$ the measured mechanical power and $P_{e}$ the measured electrical active power.

The results can be processed, to give interesting compared results, as depicted in Figures 12, 13, 14, and 15.

The obtained results are more readable if the obtained results in nonsinusoidal condition are referred to the sinusoidal one. The obtained results are reported in Figure 15 in which $D[\%]$ is obtained, respectively, as follows:

$$
\begin{gathered}
\frac{\eta_{\text {distorted }}-\eta_{\text {sinusoidal }}}{\eta_{\text {sinusoidal }}} * 100 \\
\frac{\eta_{\text {unbalanced }}-\eta_{\text {sinusoidal }}}{\eta_{\text {sinusoidal }}} * 100 .
\end{gathered}
$$

In the picture it is evident that the distortion has no effect at high load while the unbalance shows an effect which rises as the load increases till the value of about $5 \%$ at the rated load.

\section{Future Trends}

Recently, new high-performance and low-cost measuring devices have been introduced into the market. Moreover new 


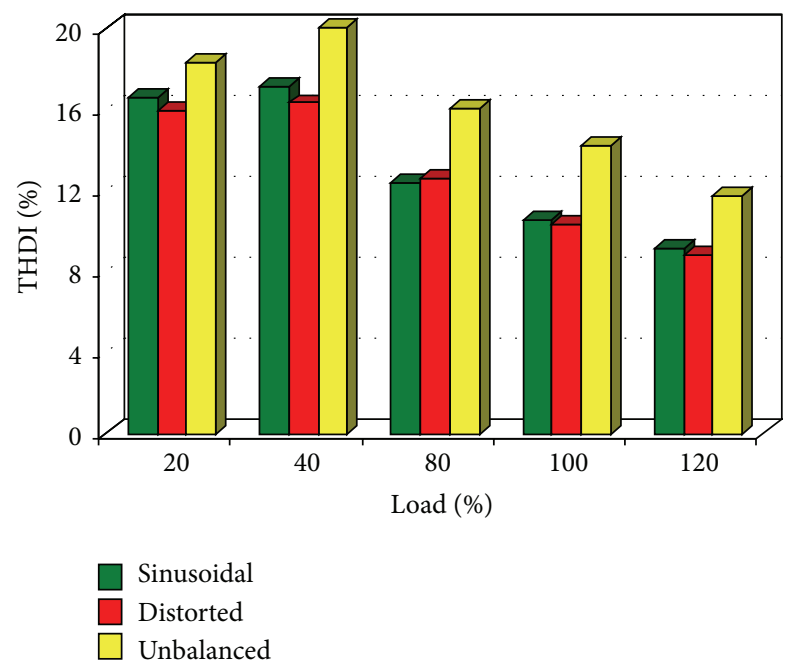

FIGURE 12: Comparison among THDI under different supply voltage conditions for phase R.

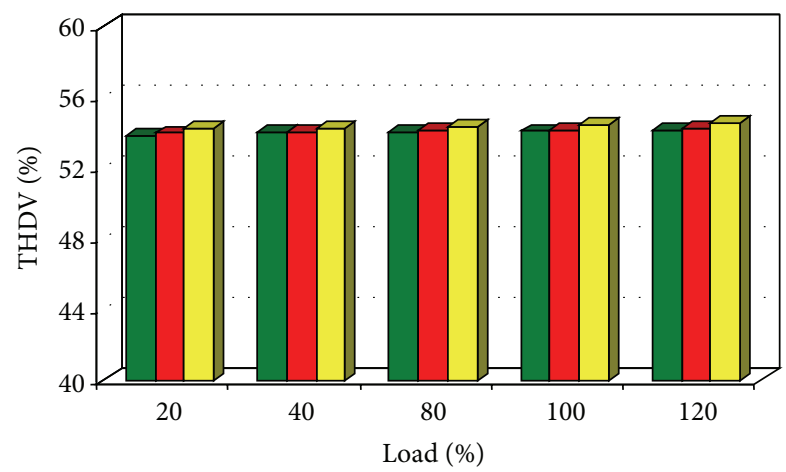

Sinusoidal
Distorted

Figure 13: Comparison among THDV of phase R under different supply voltage conditions.

advanced measurement techniques have emerged as promising approach to providing better performances to the measuring system.

As the electrical signals are concerned, the more interesting devices are the Hall based voltage and current transducers. As previously stated the current transducer represents one of the most critical elements of the measuring chain.

The main reason is the wider signal bandwidth that demands a good linearity on a large frequency range.

As an example of the performance of these new devices, in Table 17 the main features of an industrial LEM transducer are reported [61]. This device presents an excellent linearity and stability (both versus time and temperature) over a wide bandwidth $(100 \mathrm{kHz})$. Similar or worse performances in the past were available only for special high-cost measuring apparatus.

But what is really changing is the measurement of the torque. Conventional methods of measuring torque on electric motors yield accurate values for a constant or slowly varying torque.

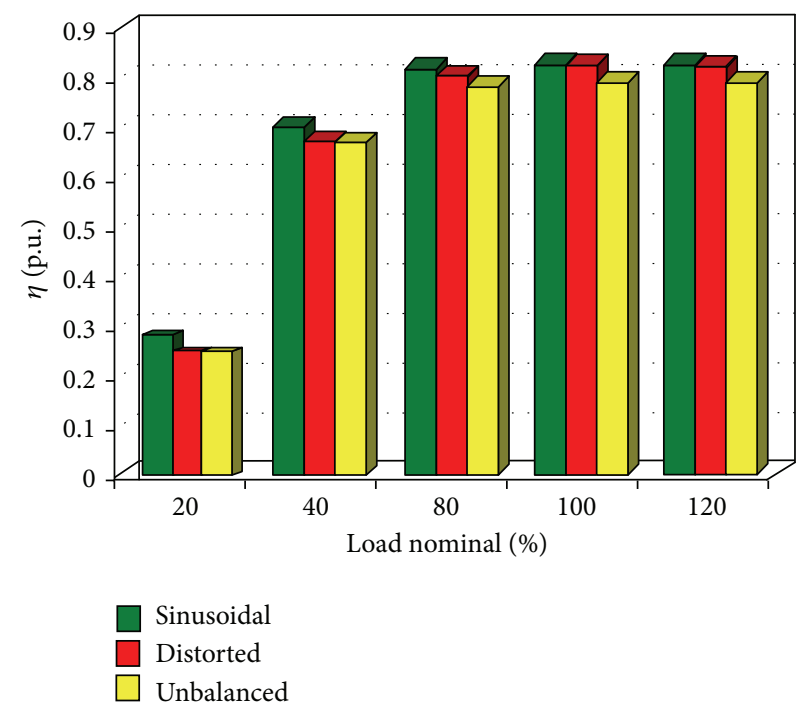

FIGURE 14: Efficiency comparison among different supply conditions.

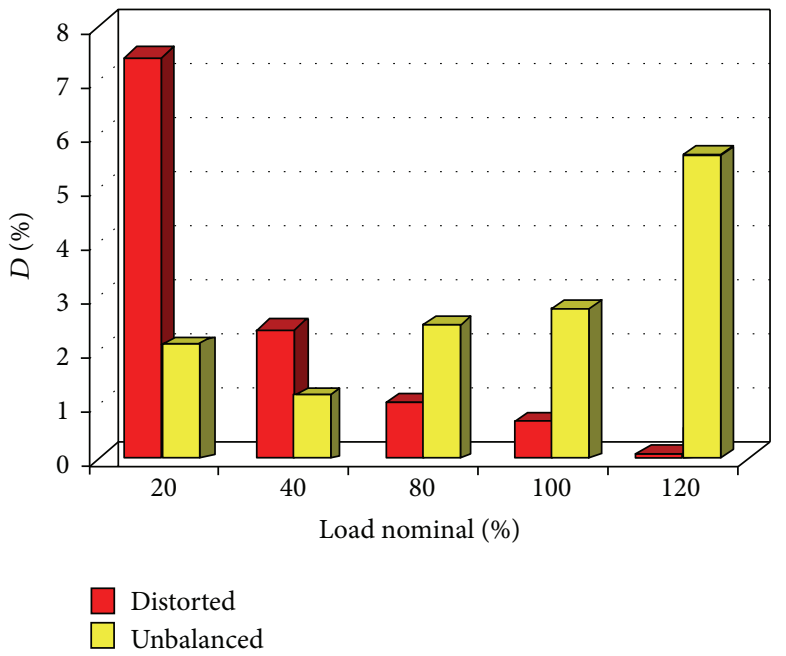

FIGURE 15: Relative Difference between the efficiency in distorted and unbalanced working condition versus sinusoidal waveform supply.

Some limits regarding their dynamic behaviour are given, that is, the motor rotor inertia, which influences the results of mechanical measuring methods.

A new approach does not need mechanical elements such as shaft position transducers or strain gauges.

The measuring system uses the acquisition of the instantaneous values of the stator currents and voltages to compute the electromagnetic torque. This real-time determination of the torque can be applied to the most common type of electric motors, symmetrical three phase, in steady-state and transient conditions.

This solution means fundamental advantages for many technical applications. Transient torque and fast internal pendulum torque, which can lead to serious damages of windings or bearings, can be measured.

Another advantage is that mechanical sensor installation is not required. This performance is very valuable in some 
TABLE 17: Specifications of LEM IT 150-S current transducer.

\begin{tabular}{lc}
\hline Input current $(\max )$ & $150 \mathrm{~A}$ \\
Output current $(\max )$ & $200 \mathrm{~mA}$ \\
Linearity & $<1 \mathrm{ppm}$ \\
Stability & $<2 \mathrm{ppm}$ \\
Stability versus temperature & $<0.3 \mathrm{ppm} /{ }^{\circ} \mathrm{C}$ \\
Stability versus time & $<1 \mathrm{ppm} / \mathrm{month}$ \\
Output noise (DC-10 Hz) & $<0.04 \mu \mathrm{A}$ \\
Output noise (DC-10 kHz) & $<2.4 \mu \mathrm{A}$ \\
Output noise (DC-50 kHz) & $<8 \mu \mathrm{A}$ \\
di/dt & $>100 \mathrm{~A} / \mu \mathrm{s}$ \\
Frequency bandwidth & $\mathrm{DC}-100 \mathrm{kHz}$ \\
Test voltage & $5 \mathrm{kV} \mathrm{AC}(\mathrm{RMS})$ \\
\hline
\end{tabular}

cases, when the site is difficult or dangerous to access and it may not be practical to install a mechanical measuring device. Moreover mechanical measuring devices must be selected based on the motor speed and size. Then a set of devices are required when working with a variety of motors. The use of the dynamic digital transient torque measurement removes limits to the torque and speed ranges and is safe from overload peaks.

Smart power measurement devices can be successfully embedded in the VSD, with the aim of evaluating the features of the supply voltage waveforms and measuring the actual power and energy consumption of the VSD [62-66].

\section{Conclusions}

In this paper the state and the trends of measurement techniques and instruments applied for the experimental characterization of variable speed drives are presented and discussed; the problems related to the measurement of electrical and mechanical quantities and related to sensorless control for electric motors are presented, with a particular attention to the case of non sinusoidal supply waveforms. PQ phenomena and their effects on VSD are also considered, and an experimental setup for the VSD testing in these condition is proposed.

\section{References}

[1] J. Holtz, "Sensorless control of induction machines-with or without signal injection?" IEEE Transactions on Industrial Electronics, vol. 53, no. 1, pp. 7-30, 2006.

[2] K. Lee and G. Nojima, "Quantitative power quality and characteristic analysis of multilevel pulsewidth-modulation methods for three-level neutral-point-clamped medium-voltage industrial drives," IEEE Transactions on Industry Applications, vol. 48, no. 4, pp. 1364-1373, 2012.

[3] D. Gallo, M. Luiso, and N. Pasquino, "Experimental evaluation of the incidence of operating conditions on measurement uncertainty of conducted emissions by power drive systems," in Proceedings of the IEEE Instrumentation and Measurement Technology Conference (IMTC '06), pp. 1705-1710, Sorrento, Italy, April 2006.
[4] G. Acampora, C. Landi, M. Luiso, and N. Pasquino, "Optimization of energy consumption in a railway traction system," in Proceedings of the International Symposium on Power Electronics, Electrical Drives, Automation and Motion (SPEEDAM '06), pp. 1121-1126, Taormina, Italy, May 2006.

[5] C. Landi and M. Luiso, "Performances assessment of electrical motors in presence of disturbances on power supply," in Proceedings of the International Symposium on Power Electronics, Electrical Drives, Automation and Motion (SPEEDAM '08), pp. 167-172, Ischia, Italy, June 2008.

[6] http://www.lem.com/hq/en/component/option.com_catalog/ taskdisplayserie/serieCV\%7B\%25\%7D203-Voltage/output_ type/.

[7] http://www.home.agilent.com/en/pd-1000001297:epsg:pro-pn3458A/digital-multimeter-8-digit?\&cc=IT\&lc=ita.

[8] http://www.prema.com/D/JVSe.htm.

[9] http://assets.fluke.com/manuals/187_189_umeng0200.pdf.

[10] http://www.keithley.it/products/dcac/dmm/highper/?mn= 2002.

[11] http://www.fluke.com/fluke/uses/Fluke-1281.htm?PID=56003.

[12] http://www.power-e.de/Literatur/Demands_for_Power_Measurement_at_Converters.pdf.

[13] F. Avallone, C. de Capua, and C. Landi, "Measurand reconstruction techniques for power measurements on high efficiency variable speed drives," in Proceedings of the 14th IMEKO World Congress, Tampere, Finland, June 1997.

[14] G. Bucci, A. Germano, and C. Landi, "Real-time harmonics estimation on power system by means of a transputer-based measurement apparatus," in Proceedings of the 13th IMEKO World Congress, pp. 1276-1281, Turin, Italy, September 1994.

[15] G. Bucci and C. Landi, "On-line power measurement in nonsinusoidal condition by using a FRLS algorithm," in Proceedings of the 7th Symposium on Modern Electrical and Magnetic Measurement (IMEKO-TC4'95), pp. 676-680, Prague, Czech Republic, September 1995.

[16] G. Bucci, F. Avallone, C. de Capua, and C. Landi, "Comparative analysis among real-time power measurement on PWM-Fed systems," in Proceedings of the 8th Symposium on New Measurements and Calibration Methods of Electrical Quantities and Instruments (IMEKO TC-4 '96), pp. 242-245, Budapest, Hungary, September 1996.

[17] G. Bucci, C. de Capua, and C. Landi, "Power measurements on high distorted signals: experimental comparison between two alternative developed device solutions," Measurement, vol. 23, no. 3, pp. 151-158, 1998.

[18] G. Bucci and C. Landi, "On-line digital measurement for the quality analysis of power systems under non-sinusoidal conditions," in Proceedings of the Joint IEEE Instrumentation and Measurement Technology Conference \& IMEKO Technical Committee (IMTC '96), pp. 934-938, Brussels, Belgium, June 1996.

[19] G. Bucci, C. de Capua, and C. Landi, "Power measurements," in Encyclopedia of Electrical and Electronics Engineering, pp. 716733, John Wiley \& Sons, 1999.

[20] P. Arpaia, F. Avallone, A. Baccigalupi, C. de Capua, and C. Landi, "Power measurement," in The Measurement, Instrumentation and Sensors Handbook, J. Webster, Ed., CRC Press, Boca Raton, Fla, USA, 1997.

[21] F. Avallone, C. de Capua, and C. Landi, "Metrological performance improvement for power measurements on variable speed drives," in Proceedings of the Power Electronics, Industrial Drives, Power Quality and Traction Systems (SPEEDAM '96), Capri, Italy, June 1996. 
[22] F. Avallone, C. de Capua, and C. Landi, "A digital technique based on real-time error compensation for high accuracy power measurement on variable speed drives," in Proceedings of the IEEE Instrumentation \& Measurement Technology Conference (IMTC '97), pp. 201-206, Ottawa, Canada, May 1997.

[23] F. Avallone, C. de Capua, and C. Landi, "Measurement station performance optimization for testing on high efficiency variable speed drives," in Proceedings of the Joint IEEE Instrumentation and Measurement Technology Conference \& IMEKO Technical Committee (IMTC '96), pp. 1098-1103, Brussels, Belgium, June 1996.

[24] http://www.fluke.com/fluke/usen/Power-Quality-Tools/HighPrecision-Power-Analyzers/Fluke-Norma-4000-5000.htm? $\mathrm{PID}=56163$.

[25] G. Bucci and C. Landi, "Metrological characterization of a contactless smart thrust and speed sensor for linear induction motor testing," IEEE Transactions on Instrumentation and Measurement, vol. 45, no. 2, pp. 493-498, 1996.

[26] H. H. Bau, N. F. de Rooij, and B. Kloeck, "Mechanical sensor," in Sensors: A Comprehensive Survey, vol. 7, VCH, 1994.

[27] J. R. Cameron, W. T. Thomson, and A. B. Dow, "Vibration and current monitoring for detecting airgap eccentricity in large induction motors," IEE Proceedings B, vol. 133, no. 3, pp. 155-163, 1986.

[28] http://www.hbm.com/en/menu/products/transducers-sensors/torque/?geoip_cn=1.

[29] T. D. Batzel and K. Y. Lee, "Electric propulsion with sensorless permanent magnet synchronous motor: implementation and performance," IEEE Transactions on Energy Conversion, vol. 20, no. 3, pp. 575-583, 2005.

[30] M. E. Elbuluk and M. D. Kankam, Speed Sensorless Induction Motor Drives for Electrical Actuators: Schemes, Trends and Tradeoffs, NASA Technical Memorandum 107466, 1997.

[31] M. Barut, R. Demir, E. Zerdali, and R. Inan, "Real-time implementation of bi input-extended Kalman filter-based estimator for speed-sensorless control of induction motors," IEEE Transactions on Industrial Electronics, vol. 59, no. 11, pp. 41974206, 2012.

[32] S. Jafarzadeh, C. Lascu, and M. S. Fadali, "State estimation of induction motor drives using the unscented Kalman filter," IEEE Transactions on Industrial Electronics, vol. 59, no. 11, pp. 42074216, 2012.

[33] Y.-R. Kim, S.-K. Sul, and M.-H. Park, "Speed sensorless vector control of induction motor using extended Kalman filter," IEEE Transactions on Industry Applications, vol. 30, no. 5, pp. 12251233, 1994.

[34] Y.-S. Kim, S.-U. Kim, and I.-W. Yang, "Implementation of a speed sensor-less vector control of induction motor by reducedorder extended Kalman filter," in Proceedings of the 10th IEEE Annual Applied Power Electronics Conference (APEC '95), pp. 197-203, Dallas, Tex, USA, March 1995.

[35] B. J. Brunsbach, G. Henneberger, and T. Klesch, "Realization of a sensorless field-oriented controlled drive of an induction motor with a Kalman filter," in Proceedings of the 19th International Conference on Intelligent Motion (PCIM '91), pp. 53-64, Nürnberg, Germany, June 1991.

[36] F. Bonanno, A. Consoli, A. Raciti, and A. Testa, "An innovative direct self-control scheme for induction motor drives," IEEE Transactions on Power Electronics, vol. 12, no. 5, pp. 800-806, 1997.
[37] M. Depenbrock, "Direct self-control (DSC) of inverter-fed induction machine," IEEE Transactions on Power Electronics, vol. 3, no. 4, pp. 420-429, 1988.

[38] S. Ziaeinejad, Y. Sangsefidi, H. P. Nabi, and A. Shoulaie, "Direct torque control of two-phase induction and synchronous motors," IEEE Transactions on Power Electronics, vol. 28, no. 8, pp. 4041-4050, 2013.

[39] J. Faiz, M. B. B. Sharifian, A. Keyhani, and A. B. Proca, "Sensorless direct torque control of induction motors used in electric vehicle," IEEE Transactions on Energy Conversion, vol. 18, no. 1, pp. 1-10, 2003.

[40] J. Faiz, M. B. B. Sharifian, A. Keyhani, and A. B. Proca, "Sensorless direct torque control of induction motors used in electric vehicle," IEEE Transactions on Energy Conversion, vol. 18, no. 1, pp. 1-10, 2003.

[41] K. Matsus and S. Katsuta, "Fast rotor flux control of vector controlled induction motor operating at maximum efficiency for electric vehicles," in Proceedings of the 13th International Electric Vehicle Symposium (IEVS '96), pp. 272-278, 1996.

[42] J. Faiz, S. H. Hossieni, M. Ghaneei, A. Keyhani, and A. Proca, "Direct torque control of induction motors for electric propulsion systems," Electric Power Systems Research, vol. 51, no. 2, pp. 95-101, 1999.

[43] U. Baader, M. Depenbrock, and G. Gierse, "Direct self control (DSC) of inverter-fed induction machine: a basis for speed control without speed measurement," IEEE Transactions on Industry Applications, vol. 28, no. 3, pp. 581-588, 1992.

[44] O. Kukrer, "Discrete-time current control of voltage-fed threephase PWM inverters," IEEE Transactions on Power Electronics, vol. 11, no. 2, pp. 260-269, 1996.

[45] T. G. Habetler, F. Profumo, M. Pastorelli, and L. M. Tolbert, "Direct torque control of induction machines using space vector modulation," IEEE Transactions on Industry Applications, vol. 28, no. 5, pp. 1045-1053, 1992.

[46] P. Vas, Sensorless Vector and Direct Torque Control, Oxford University Press, New York, NY, USA, 1998.

[47] J. Faiz and M. B. B. Sharifian, "Different techniques for real time estimation of an induction motor rotor resistance in sensorless direct torque control for electric vehicle," IEEE Transactions on Energy Conversion, vol. 16, no. 1, pp. 104-110, 2001.

[48] A. Taheri, A. Rahmati, and S. Kaboli, "Efficiency improvement in DTC of six-phase induction machine by adaptive gradient descent of flux," IEEE Transactions on Power Electronics, vol. 27, no. 3, pp. 1552-1562, 2012.

[49] G. Bucci, E. Fiorucci, F. Ciancetta, and N. Rotondale, "A testing system for the performance evaluation of electrical machines under realistic voltage fluctuations," in Proceedings of the IEEE International Instrumentation and Measurement Technology Conference (I2MTC '10), pp. 1441-1446, Austin, Tex, USA, May 2010.

[50] "IEEE Draft Guide for the Application of Power Electronics for Power Quality Improvement on Distribution Systems Rated 1 kV through 38 kV,"1409/D15, pp. 1-92, 2012.

[51] "IEEE Guide for Identifying and Improving Voltage Quality in Power Systems," IEEE Std 1250-2011, pp. 1-70, 2011.

[52] "IEEE Recommended Practice for Monitoring ElectricPower Quality," IEEE Std 1159-2009 (Revision of IEEE Std 1159-1995), pp. c1-81, 2009.

[53] IEC, 61000-4-30 ED. 2.0 B:2008, "Electromagnetic compatibility (EMC) - part 4-30: testing and measurement techniquespower quality measurement methods". 
[54] EN 50160/EC:2010-12, "Voltage characteristics of electricity supplied by public distribution networks," 2010.

[55] IEC 61000-2-4, "Environment-compatibility levels in industrial plants for low-frequency conducted disturbances," June 2002.

[56] http://www.atecorp.com/products/pacific-power/3120amx. aspx.

[57] http://www.magtrol.com/motortest/hd_specifications.html.

[58] http://www.magtrol.com/manuals/dsp6000manual.pdf.

[59] http://www.ni.com/pxi/.

[60] G. Bucci, E. Fiorucci, A. Ometto, and N. Rotondale, "The evaluation of the effects of the voltage amplitude modulations on induction motors," in Proceedings of the IEEE Russia Power Tech (Powertech '05), St. Petersburg, Russia, June 2005.

[61] http://www.gmw.com/electric_current/LEM/docs/LEM-DS_it_ 150-s_ultrastab.pdf.

[62] C. Landi, M. Luiso, and N. Pasquino, "A remotely controlled onboard measurement system for optimization of energy consumption of electrical trains," IEEE Transactions on Instrumentation and Measurement, vol. 57, no. 10, pp. 2250-2256, 2008.

[63] G. del Prete, D. Gallo, C. Landi, and M. Luiso, "The use of real-time instruments for smart power systems," in Proceedings of the IEEE International Energy Conference and Exhibition (ENERGYCON '12), pp. 884-889, Florence, Italy, September 2012.

[64] G. Bucci, E. Fiorucci, F. Ciancetta, D. Gallo, C. Landi, and M. Luiso, "Embedded power and energy measurement system based on an analog multiplier," IEEE Transactions on Instrumentation and Measurement, vol. 62, no. 8, pp. 2248-2257, 2013.

[65] D. Gallo, C. Landi, M. Luiso, G. Bucci, and E. Fiorucci, "Low cost smart power metering," in Proceedings of the IEEE International Instrumentation and Measurement Technology Conference (I2MTC '13), Minneapolis, Minn, USA, May 2013.

[66] G. Bucci, F. Ciancetta, E. Fiorucci, D. Gallo, and C. Landi, "A low cost embedded web services for measurements on power system," in Proceedings of the IEEE International Conference on Virtual Environments, Human-Computer Interfaces, and Measurement Systems (VECIMS '05), pp. 7-12, Giardini Naxos, Itay, June 2005. 

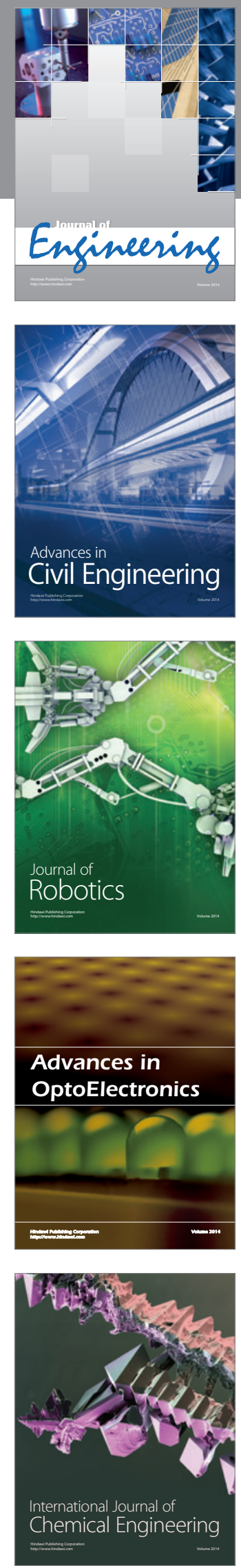

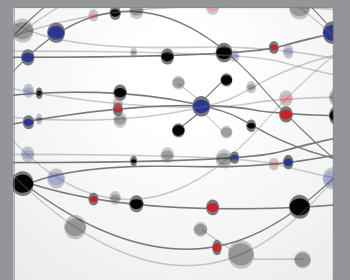

The Scientific World Journal
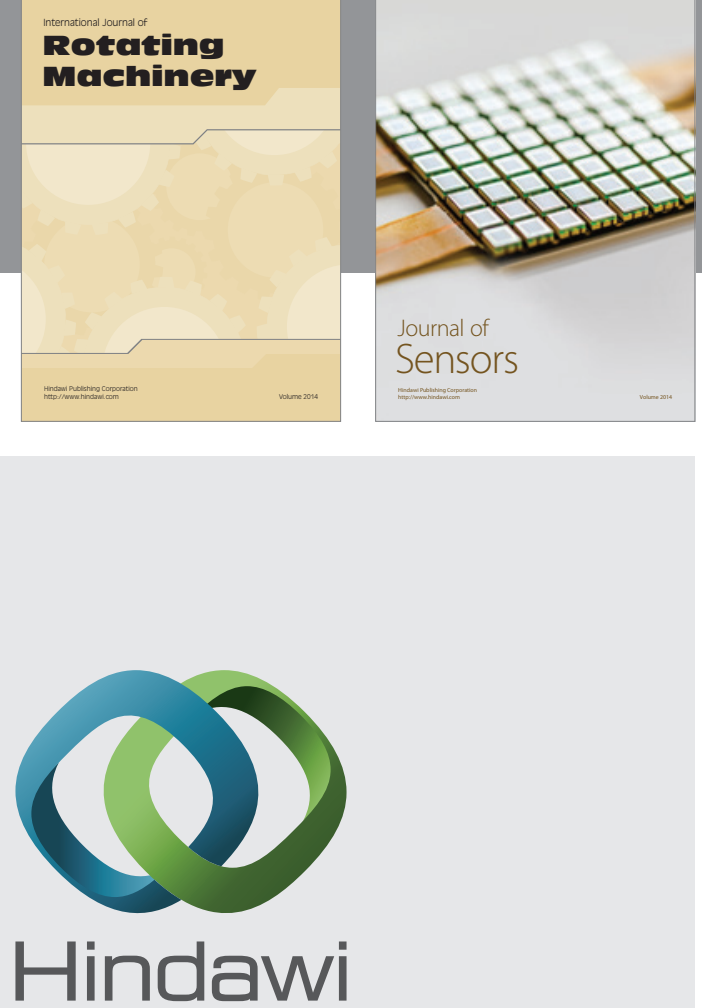

Submit your manuscripts at http://www.hindawi.com
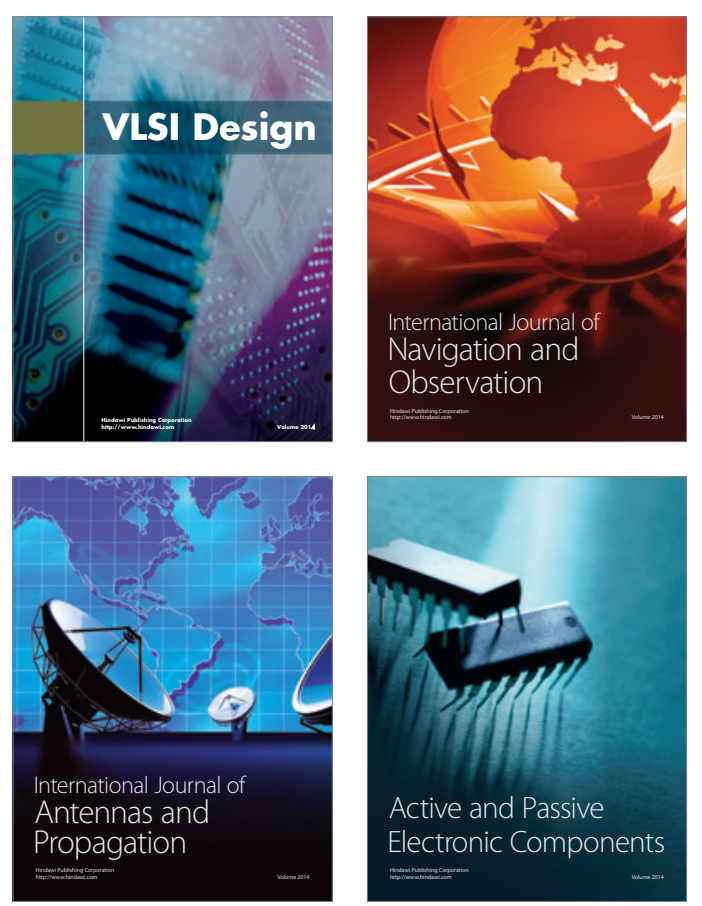
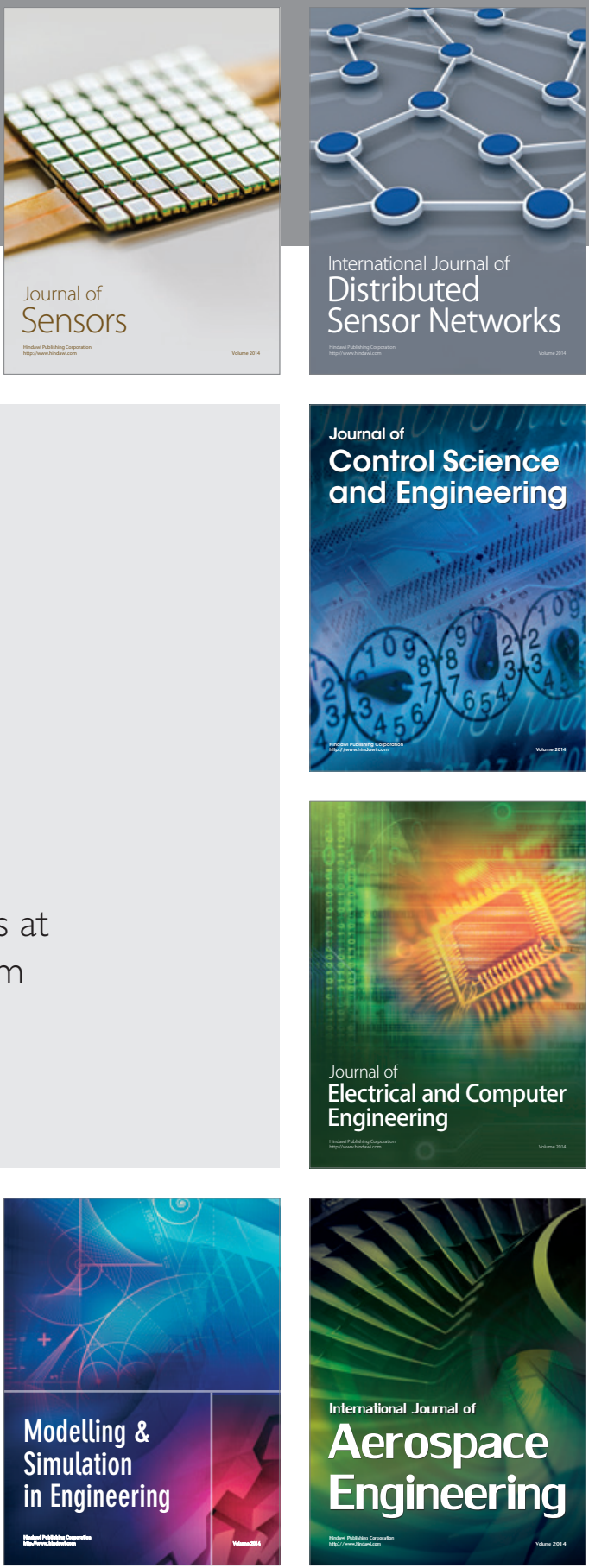

Journal of

Control Science

and Engineering
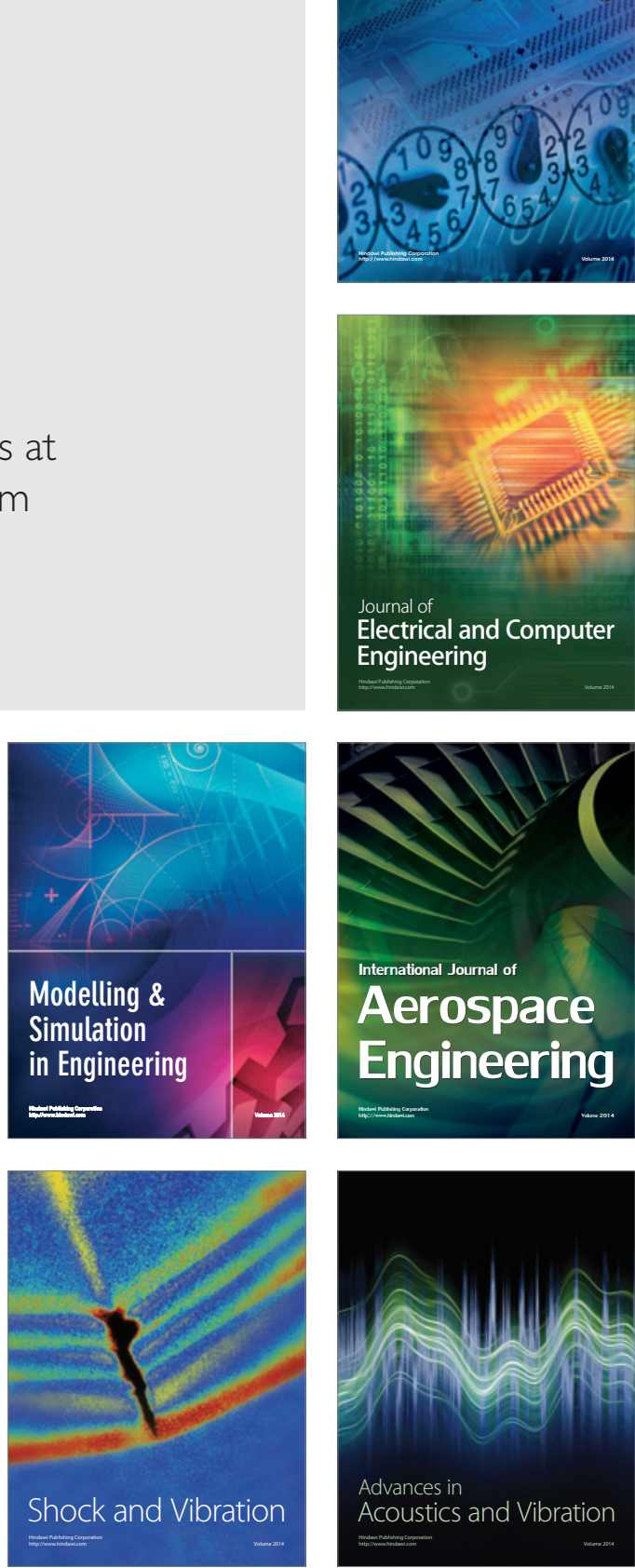